\title{
DIE CAMPAGNA VON SIENA
}

\author{
WILLy Meyer \\ Mit einer Farbtafel aus dem Buch*
}

Das Gebiet, das die Provinz Siena, eine der südlichsten der Toscana, umfaßt, ist Hügelland, das sich nur an drei Stellen: dem Monte Amiata mit 1734, dem Monte Cetona mit 1148 und dem Peggio di Montieri mit $1051 \mathrm{~m}$, zu Mittelgebirgshöhe erhebt. Land- und Forstwirtschaft bilden zu fast $95 \%$ den Lebenserwerb der Bevölkerung; allein $3 / 4$ derselben (von elfjährigen Kindern ab gerechnet) sind landwirtschaftlich tätig. Korn, Rebe und Ölbaum spielen eine Hauptrolle; bezüglich des Rebbaus braucht nur an den Chianti erinnert zu werden. Bedeutend ist die Viehzucht: Rinder-, Schaf-, Schweine- und Pferdezucht. Milchwirtschaft gibt es im Bereich der Crete, toniger Gratketten, die grau bis graugelb, vegetationslos, an sich ein melancholischer Anblick, doch stellenweise, nämlich da, wo sie in besonders markanten Wellenfolgen hintereinander geschichtet sind, einer ernsten Größe nicht entbehren. Bei Monteroni wirken die Crete wie eine Urweltlandschaft. Im Bereich dieser Crete also wird Milchwirtschaft getrieben und ein vorzüglicher Käse produziert, zum Beispiel in der Gegend von Chiusure, nicht weit vom berühmten Kloster Monte Oliveto Maggiore.

Zur Urbarmachung des steinigen Bodens wird viel getan, namentlich in der Zone, die von Orvietale zum Amiata führt und an die Maremmenlandschaft der Nachbarprovinz Grosseto (einst Teil der alten Republik Siena) grenzt. Einen stärkeren Gegensatz als den zwischen den Crete und dem Kulturland von Siena kann man sich kaum denken. Dies Kulturland umfaßt die landwirtschaftlichen und die Waldbezirke. Der Reisende, der das sienesische Bauernland einmal erlebt hat, wird es nie wieder vergessen: allenthalben durchsetzen es isolierte Hügel und diese Hügel tragen Bauernhöfe, die Zypressen und Schober umgeben, die man gern zu förmlichen Bauten, sei es in Hütten-, sei es in Bienenkorbform, gestaltet. Fährt man an sommerlichen Spätnachmittagen durch das wellige Land, so sieht man zahllose Tiere auf der Weide, besonders viele Schweine. Die Bewässerung des Erdreichs macht nicht selten große Schwierigkeiten. Die meisten Flüsse der Provinz trocknen in den heissen Monaten bis in den Oktober hinein! - fast oder ganz aus, Regen ist selten. An stehenden Gewässern besitzt das Land nur die zwei kleinen Seen von Montepulciano und Chiusi, Reste eines bonifizierten Sumpfbodens, die aber zur Verödung verurteilt sind, weil ihnen Geschiebe durch einen Fluß immer mehr «Lebensraum» entzieht.

Die wasserrreichste Gegend der Provinz liegt in ihrem Süden, wo sich als höchster toskanischer Berg südlich des Arno der Amiata erhebt. Er ist die schönste Waldzone des Landes und seine Bäume, vorab die prächtigen Eichen und Kastanienbäume, sind reine Zierde. Seit alters wird der Amiata mit Erfolg nach Heilkräutern abgesucht; eine Sage läßt das von einer Seuche befallene Heer Karls des Großen durch solche gerettet werden, und Papst Pius II (der gefeierte Humanist Aenea Sylvio Piccolomini) berichtet von den zahlreichen Apothekern, die von ziemlich weit her in dieses Gebirge kommen, um sich mit den hochgeschätzten Kräutern zu versehen. Endlich ist am Amiata noch eine besondere Einahmequelle der campagna sienese, nämlich Quecksilberminen, die seit Etruskerzeiten bis auf den heutigen Tag ausgebeutet werden. Das sienesische Land blickt auf eine mindestens zweieinhalbtausendjährige Kultur zurück.

\section{$L A$ «AMPAGNA》DE SIENNE}

La «Campagna»de Sienne est le nom de la région qui s'étend autour de la ville du même nom. C'est surtout une contrée de collines qui atteint seulement au Monte Amiata, au Monte Cetona et à Peggio di Montieri des altitudes de montagnes moyennes. La «Campagna»est une région avant tout agraire dans laquelle l'élevage du bétail joue le rôle principal; toutefois le sol pierreux et sec rend son utilisation assez difficile. Les mines de mercure qui sont exploitées depuis l'époque étrusque constituent une source particulière de revenus. Ainsi, depuis 2500 ans, le pays de Sienne est marqué par la civilisation humaine.

* Abendländisches Erlebnis, Siena und seine Welt. Verlag Kümmerly \& Frey, Bern. 44 


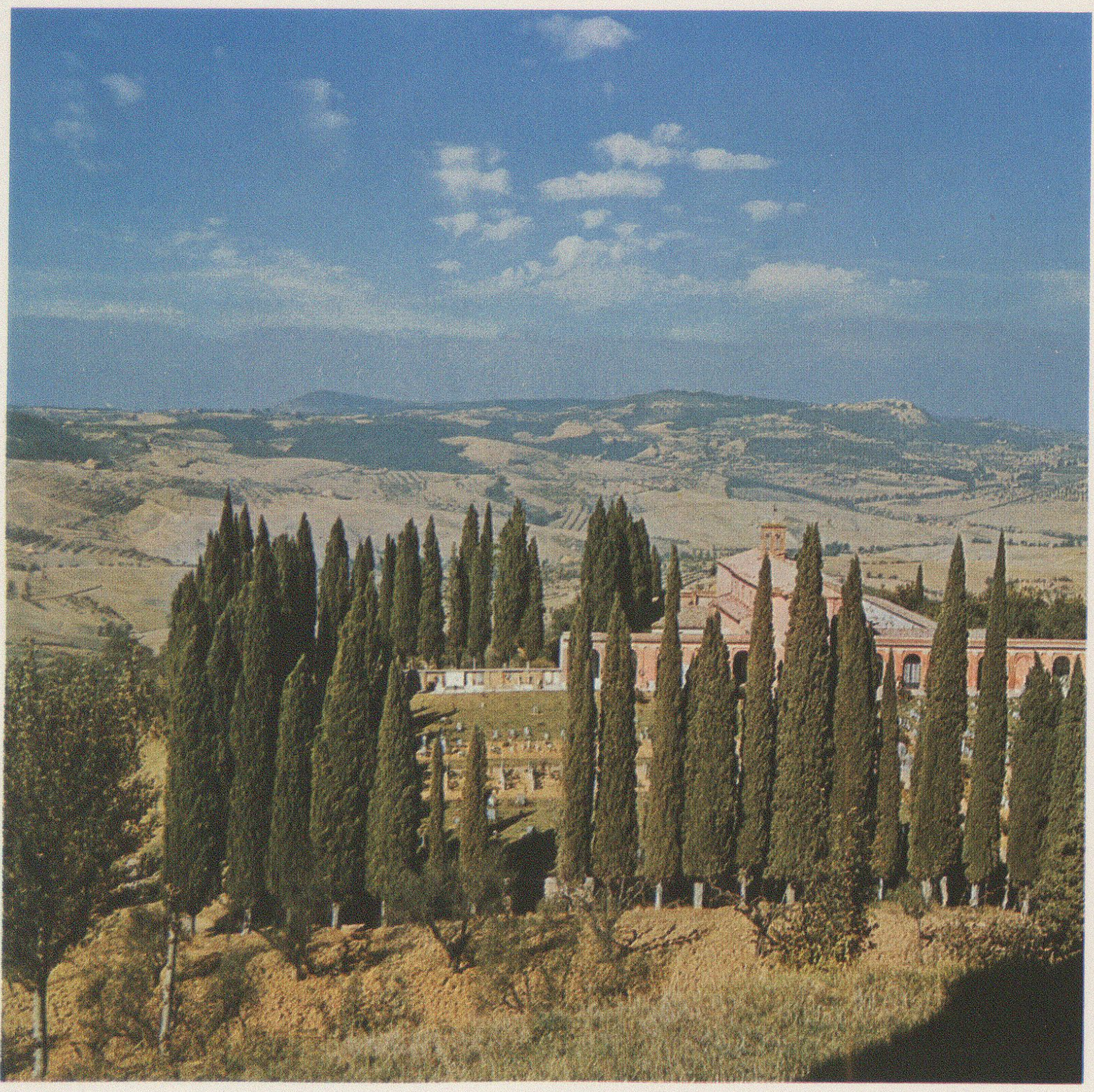

LANDSCHAFT BEI MONTEPULCIANO

Der Zypressenhain des Cimitero Nuovo 